See Article page 1820.

\section{Commentary: Transventricular mitral valve repair: Are we ready to move in reverse to repair P2 prolapse?}

Federico Milla, MD, and Vinod H. Thourani, MD

Budra and colleagues ${ }^{1}$ report their single center, midterm experience with the DS1000 Neochord (NeoChord Inc, St Louis Park, Minn) transventricular mitral valve (MV) repair system. ${ }^{1}$ This is a beating-heart, transapical device that captures and attaches polytetrafluoroethyelene chords to the prolapsing segment of the MV and exteriorizes the chords to the left ventricular (LV) epicardium while providing tension to the repaired prolapse leaflet. They reported outcomes of 89 patients who underwent the procedure between 2011 and 2017, with a wide range of prolapse pathology, including 22 isolated P2 segment prolapses (type A), 47 multisegment posterior leaflet prolapses (type B), 15 bi-leaflet and/or commissural prolapses (type C), and 4 isolated anterior leaflet prolapses (type D). Immediate procedural reduction of mitral regurgitation (MR) to $\leq 2+$ was noted in $98 \%$, and trace to no MR was noted in $69.3 \%$. Operative mortality was $1 \%$ due to cardiac tamponade in 1 patient on postoperative day 2 leaving 88 patients for follow-up. Overall freedom from $\geq 2+\mathrm{MR}$ at $1,6,12,24$, and 36 months was $86 \%, 77 \%, 72 \%, 59 \%$, and $49 \%$, respectively. Acceptable MR reduction was achieved in $82 \%$ of patients with type A prolapse, whereas only $20 \%$ of patients with type $C$ prolapse were free of $\geq 2+M R$. The authors found that patients with an increased risk of

\footnotetext{
From the Department of Cardiovascular Surgery, Marcus Valve Center, Piedmont Heart Institute, Atlanta, Ga.

Disclosures: Dr Milla has received consulting fees from Valgen Holding Corporation/ MitralStitch Device and Dr Thourani has conducted advisor/research work for Abbott Vascular, Edwards Lifesciences, Boston Scientific, Medtronic, Gore Vascular, Shockwave, and Jenavalve.

The Journal policy requires editors and reviewers to disclose conflicts of interest and to decline handling or reviewing manuscripts for which they may have a conflict of interest. The editors and reviewers of this article have no conflicts of interest.

Received for publication Dec 18, 2020; revisions received Dec 18, 2020; accepted for publication Dec 21, 2020; available ahead of print Dec 25, 2020.

Address for reprints: Vinod H. Thourani, MD, Department of Cardiovascular Surgery, Marcus Valve Center, Piedmont Heart Institute, 95 Collier Rd, Suite 5015, Atlanta, GA 30308 (E-mail: vinod.thourani@piedmont.org).

J Thorac Cardiovasc Surg 2022;164:1829-30

$0022-5223 / \$ 36.00$

Copyright (c) 2021 by The American Association for Thoracic Surgery

https://doi.org/10.1016/j.jtcvs.2020.12.084
}

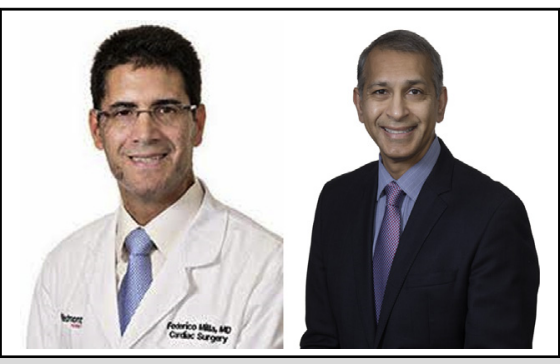

Federico Milla, MD, and Vinod H. Thourani, MD

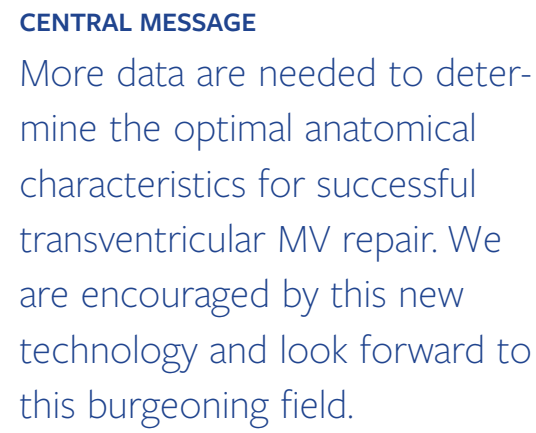

recurrent MR included type $C$ pathology and patients with pre-existing LV enlargement.

This is an important study and we congratulate the investigators for this seminal work and detailed follow-up. Their results correlate outcomes reported by Colli and colleagues $^{2,3}$ from a multi-center registry demonstrating $74 \%$ and $72 \%$ freedom from $\geq 2+\mathrm{MR}$, respectively. However, the current study lacks some important technical data such as chordal placement on the LV access site (eg, trueapex vs anterior vs posterior ventricular approach). The access location might not only allow the operator to better reach the prolapsing segment, but also may provide an ability to adjust the degree of and location of displacement of the prolapsing segment, which could influence durability. An example of this is a posterior lateral approach with overtensioning of the prolapsing segment that may allow the chords to remain under optimal tension even after ventricular reverse remodeling has occurred. This was highlighted in this study where risk of recurrent MR was increased if there was significant LV enlargement before the procedure. Because the chords are attached to the outer ventricular wall farther away from the MV annulus relative to native chordae, reverse remodeling of the ventricle could lead to laxity of the neochords and recurrence of prolapse. An anterior approach, on the other hand, could allow better coaptation of the repaired segment with the anterior leaflet because it draws the posterior leaflet toward the middle of the valve, mimicking an annuloplasty effect. Additional data that 
could also determine durability are the number of chords used per prolapsing segment. More chords may better distribute tension and prevent tearing, as well as provide a more uniform correction of prolapse.

The 2 transapical systems currently being investigated in the United States are the DS1000 Neochord (used in the current study) and the Harpoon Medical Device (Edwards LifeSciences, Irvine, Calif). ${ }^{4,5}$ The ongoing Randomized Trial of the Neochord DS1000 System Versus Open Surgical Repair (ReChord) trial, a randomized trial comparing transapical MV repair with the DS1000 Neochord device with conventional surgery may help determine differences in durability between the 2 groups. The RESTORE trial using the Harpoon Medical Device is a prospective multicenter single-arm trial with a safety end point (comparing with conventional MV surgery as matched via the Society of Thoracic Surgeons database) and an effectiveness end point (comparing echocardiograms for recurrence of MR from patients within a National Institutes of Health trial on mitral and tricuspid valve repair).

There remains skepticism among many cardiac surgeons on the utility of transapical mitral repair; mostly due to the inability to place a band or ring for support of the MV annulus. Furthermore, some may view these data as not at par with some excellent prior surgical series. ${ }^{6}$ However, it should be noted that there remains a paucity of adjudicated echocardiogram follow-up in the modern surgical era for degenerative surgical repair and a true incidence of freedom from MR has not been well evaluated.

We congratulate Budra and colleagues ${ }^{1}$ on their work. Although more data are needed to determine the optimal anatomical characteristics for successful durable transapical MV repair, we are encouraged by this new technology and look forward to this chapter in the field of mitral valve surgery.

\section{References}

1. Budra M, Janušauskas V, Drąsutiene A, Zorinas A, Zakarkaite D, Lipnevičius A, et al. Midterm results of transventricular mitral valve repair: single center experience. J Thorac Cardiovasc Surg. 2022;164:1820-8.

2. Colli A, Manzan E, Besola L, Bizzotto E, Fiocco A, Zucchetta F, et al. One-year outcomes after transapical echocardiography-guided mitral valve repair. Circulation. 2018;138:843-5.

3. Colli A, Adams DH, Fiocco A, et al. Transapical NeoChord mitral valve repair. Ann Cardiothorac Surg. 2018;7:812-20.

4. Gammie JS, Bartus K, Gackowski A, D’Ambra MN, Szymanski P, Bilewska A, et al. Beating-heart mitral valve repair using a novel ePTFE cordal implantation device: a prospective trial. J Am Coll Cardiol. 2018;71:25-36.

5. Gammie JS, Bartus K, Gackowski A, Szymanski P, Bilewska A, Kusmierczyk M, et al. Safety and performance of a novel transventricular beating heart mitral valve repair system: 1-year outcomes. Eur J Cardiothorac Surg. 2020;59:199-206.

6. David TE, David CM, Tsang W, Lafreniere-Roula M, Manlhiot C. Long-term results of mitral valve repair for regurgitation due to leaflet prolapse. J Am Coll Cardiol. 2019;74:1044-53. 